\title{
BMJ Open Association between guidelines and medical practitioners' perception of best management for patients attending with an apparently uncomplicated acute sore throat: a cross-sectional survey in five countries
}

\author{
Ronny Gunnarsson (D) , ${ }^{1,2,3}$ Mark H Ebell (D) , ${ }^{4}$ Hannelore Wächtler, ${ }^{5}$ \\ Naveen Manchal, ${ }^{6}$ Lynne Reid, ${ }^{6}$ Stefan Malmberg, ${ }^{1}$ Sean Hawkey, ${ }^{7}$ Alastair D Hay, ${ }^{8}$ \\ Katarina Hedin, ${ }^{9,10}$ Pär-Daniel Sundvall ${ }^{1,2,3}$
}

To cite: Gunnarsson $\mathrm{R}$, Ebell MH, Wächtler H, et al. Association between guidelines and medical practitioners' perception of best management for patients attending with an apparently uncomplicated acute sore throat: a cross-sectional survey in five countries. BMJ Open 2020;10:e037884. doi:10.1136/ bmjopen-2020-037884

- Prepublication history for this paper is available online. To view these files, please visit the journal online (http://dx.doi org/10.1136/bmjopen-2020037884).

Received 19 February 2020 Revised 02 July 2020 Accepted 04 August 2020

Check for updates

(c) Author(s) (or their employer(s)) 2020. Re-use permitted under CC BY-NC. No commercial re-use. See rights and permissions. Published by BMJ.

For numbered affiliations see end of article.

Correspondence to

Professor Ronny Gunnarsson; ronny.gunnarsson@infovoice.se

\section{ABSTRACT}

Objective To investigate the relationship between guidelines and the medical practitioners' perception of optimal care for patients attending with an apparently uncomplicated acute sore throat in five countries (Australia, Germany, Sweden, UK and USA). Design International cross-sectional survey. Setting Primary healthcare (PHC).

Participants Medical practitioners working in PHC. Main outcome measures ORs for: (A) perception of throat swabs as important, (B) perception of blood tests (C reactive protein, $B-E S R$ and $B$-leucocytes) as important and (C) antibiotic prescriptions if no pathogenic bacteria isolated on throat swab.

Results Guidelines differed significantly; those recommending throat swabs (Sweden and USA) were associated with practitioners perceiving them as important. The UK guideline was the only one actively discouraging the use of throat swabs. Hence, compared with the USA (reference), a throat swab showing no pathogenic bacteria increased the probability of antibiotic prescribing in the UK with OR $3.2(95 \% \mathrm{Cl} 1.7$ to 6.1$)$ for adults, whereas it reduced the probability in Sweden for adults $0 \mathrm{R} 0.35(95 \% \mathrm{Cl} 0.13$ to 0.96$)$ and children 0.19 (95\% Cl 0.069 to 0.50).

Conclusions The differences between practitioners' perceptions of best management were associated with their guidelines. It remains unclear if guidelines influenced medical practitioners' perception or if guidelines merely reflect the consensus of current practice. A larger effort should be made to reach an international consensus in high-income countries about the best management of patients attending for an uncomplicated acute sore throat.

\section{BACKGROUND}

An uncomplicated acute sore throat is a common reason for attending a primary healthcare setting (PHC). In most countries, $40 \%-86 \%$ of these patients are prescribed
Strengths and limitations of this study

- This is the first study from several countries linking medical practitioners' perception of best management with their guidelines.

- The overall response rate was high $(74 \%)$ despite the well-known difficulties in getting a high response rate in surveys handed out to medical practitioners.

- The cross-sectional design and the fact that perceptions of optimal management were used rather than actual performance are potential limitations.

antibiotics. $^{1-6}$ Antibiotic treatment may reduce the risk of rheumatic fever in situations where this is common. ${ }^{7-9}$ It has a modest effect on pain and a small effect on preventing suppurative complications. ${ }^{10}$ These possible advantages must be weighed against the possible negative effects of antibiotic prescribing, such as antimicrobial resistance and side effects.

Factors influencing antibiotic prescribing Some of the factors influencing antibiotic prescribing are: (A) the patient's propensity to visit a General Practitioner (GP) when ill, (B) the degree of access to an appointment with a GP, $(\mathrm{C})$ the decision threshold for the GP to prescribe antibiotics and (D) the actual health of the patient based on their symptoms and signs.

The patient's propensity to visit a GP is partly a personality factor ${ }^{11}$ combined with influences from government information campaigns as well as all other more or less accurate information available from friends, 
relatives, the press, social media and various internet sources.

The number of medical practitioners is increasing both in absolute numbers and on a per capita basis in most high-income countries. ${ }^{12}$ However, this is a doubleedged sword when it comes to antibiotic prescribing being both potentially good and potentially bad. There is a direct association between attendance rates and antibiotic prescribing. ${ }^{6}{ }^{13}$ Therefore, lowering the threshold to see a GP is likely to increase antibiotic prescribing. The threshold to see a GP is also lowered by the expansion of telemedicine where the patient can chat with a GP using an app on their phone. ${ }^{1415}$

The threshold for a GP to prescribe antibiotics is influenced by many factors, including their interpretation of the medical literature, experiences with previous patients, fear of litigation (in some settings), different perceptions of the degree of benefit versus harm of antibiotics, a desire to satisfy patient expectations and personal preference. ${ }^{16-20}$ GPs prescribing habits may not primarily be guided by evidence-based medicine but rather by a number of other factors including what results in a prompt and pragmatic benefit. ${ }^{21}$ Hence, guidelines may theoretically be good, but they have a tendency to work less well in clinical practice. ${ }^{22}$ Varying personal preferences and the need for a prompt and pragmatic solution result in a large proportion of medical practitioners ignoring guidelines that describe the best management of patients with a sore throat and instead developing their own individual behaviours. ${ }^{16} 18$ 22-25 This individual behaviour manifests in differing prescribing habits with a variation between GPs regarding antibiotics for sore throat with a factor between 3 and $6 .{ }^{16}{ }^{18}$ This variation in individual practitioner behaviour seems to be more pronounced in countries with less emphasis on antibiotic stewardship, less surveillance of over-the-counter sale of antibiotics and with no access to point-of-care tests (POCTs) for group A Streptococci (GAS).$^{26}$ The actual health of the patient seem to be of some importance, ${ }^{27}$ but these symptoms and signs are often misinterpreted by the physician leading to unnecessary antibiotic prescribing. ${ }^{28}$

A multitude of interventions have attempted to change GPs' prescribing of antibiotics for acute respiratory tract infections, including the sore throat. Some of these studies show a modest short-term benefit, ${ }^{29}{ }^{30}$ but it seems difficult to prove that any of the attempts so far has any long-term benefit. ${ }^{30}$

\section{Guidelines}

An important goal of guidelines for managing patients with an apparently uncomplicated acute sore throat is to influence the medical practitioners' threshold to prescribe antibiotics, making prescriptions better targeted to those patients most likely to benefit from it. The throat is easily assessible for swabbing in a way that is not possible for other respiratory tract infections such as suspected sinusitis or pneumonia. Hence, the main divider between

Table 1 Applicable guidelines in participating countries

\begin{tabular}{|c|c|c|c|c|c|}
\hline & Australia $^{34 \star}$ & Germany $^{35 *}$ & Sweden $^{36}$ & $\mathrm{UK}^{37 *}$ & USA $^{38 *}$ \\
\hline B-CRP & Not mentioned. & $\begin{array}{l}\text { CRP above a cut-off } \\
\text { between } 25-35 \mathrm{mg} / \mathrm{L}\end{array}$ & $\begin{array}{l}\text { Adds no useful } \\
\text { information. }\end{array}$ & Not mentioned. & Not mentioned. \\
\hline
\end{tabular}
may add limited information suggesting bacterial aetiology.

\begin{tabular}{|c|c|c|c|c|c|}
\hline B-ESR & Not mentioned. & $\begin{array}{l}\text { Adds no useful } \\
\text { information. }\end{array}$ & Not mentioned. & Not mentioned. & Not mentioned. \\
\hline B-leucocytes & Not mentioned. & $\begin{array}{l}\text { Adds no useful } \\
\text { information. }\end{array}$ & $\begin{array}{l}\text { Adds no useful } \\
\text { information. }\end{array}$ & Not mentioned. & Not mentioned. \\
\hline $\begin{array}{l}\text { Aetiology that } \\
\text { may trigger } \\
\text { antibiotics }\end{array}$ & GAS & GAS & GAS & Not mentioned. & GAS \\
\hline
\end{tabular}
described threshold corresponds well with $\geq 3$ Centor criteria).

\footnotetext{
*Most countries have several, more or less partly conflicting, guidelines for managing patients with an acute sore throat. The ones referred to here are those most commonly used within primary healthcare in the area where the survey was done. CRP, C reactive protein; ESR, erythrocyte sedimentation rate; GAS, group A Streptococci.
} 
different sore throat guidelines is whether to rely solely on clinical scoring of symptoms and signs or to also rely on additional information obtained from a throat swab processed using culture or a POCT to detect the presence of GAS. ${ }^{31}$ However, it seems the impact guidelines have on medical practitioners' perception of the best management strategy for these patients is limited. ${ }^{32} 33$

The primary aim of this study was to investigate difference between countries in the OR for (a) perception of throat swabs as important, (b) perception of blood tests (C reactive protein (CRP), B-ESR and B-leucocytes) as important and (C) antibiotic prescriptions if no pathogenic bacteria isolated on throat swab in patients with an apparently uncomplicated acute sore throat. The secondary aim was to explore other differences between countries in medical practitioners' perceptions. Findings will be related to what guidelines in their area recommend.

\section{METHODS}

\section{Inclusion criteria}

Medical practitioners working in a PHC setting were asked to participate by one of the authors. In most cases, this was done at meetings for continuing professional education except in Germany where most surveys were posted and later followed up by a telephone reminder. A few questionnaires were collected at personal visits to clinics during their lunch break.

\section{Data collection}

A one-page survey first asked about demographic information such as age, gender, year of graduation and experience as medical practitioner. The following questions asked about the perceived importance of different factors to guide antibiotic prescribing for patients attending with an apparently uncomplicated acute sore throat. The first question stated that 'My decision to start antibiotics would in most cases of patients with a sore throat be based on...

- History of comorbidities affecting immunity.

- History with indicative acute symptoms.

- Patient's wish to get antibiotics.

- Physical findings at examination (except fever).

- Fever $>38$ degrees Celsius/>100.4 Fahrenheit.

- Blood tests with high leucocyte count, erythrocyte sedimentation rate (ESR), C-reactive protein (CRP).

- Findings of bacteria from throat swab' (without specifying if the swab were to be analysed using culture or a POCT).

For each of these alternatives, the medical practitioner could answer in a 5-grade Likert scale with 'strongly agree', 'agree', 'neutral', 'disagree' and 'strongly disagree'.

The second question was a hypothetical case scenario describing 'a 25-year-old man presenting with a 3 day history of a sore throat and no cough. Physical examination shows red tonsils with a tonsillar exudate, tender anterior lymph nodes and temperature of $38.3 \mathrm{deg}$ Celsius/100.94 Fahrenheit. Your colleague sent a throat swab yesterday and is now unable to review the results. I would prescribe antibiotics if the throat swab showed growth of...'. A separate response was requested for growth of GAS, group C Streptococci, group G Streptococci, Fusobacterium necrophorum (FN), Haemophilus influenzae and finally if none of the previously mentioned bacteria were found. The medical practitioner could answer in a 4-grade Likert scale with 'yes definitely', 'yes probably', 'probably not' and 'definitely not'. The practitioner could also state that they had not heard of the mentioned bacteria.

The third question was another hypothetical case scenario identical to the previous other than that the patient was a 10-year-old girl.

\section{Statistical analysis}

The 5-grade Likert scale was dichotomised so that 'strongly agree' and 'agree' were merged to 'agree' and coded as 1 , while 'neutral', 'disagree' and 'strongly disagree' were merged to 'do not agree' and coded as 0 . Two multivariable binary logistic regressions were performed to answer two of the primary aims, one with agreeing that throat swab is important as the dependent variable, and the other that blood tests are important as the dependent variable. Practitioner's age, gender, being senior versus being under training and country were independent variables.

The third primary aim focused on antibiotic prescribing despite no presence of bacteria in the throat. The 4-grade Likert scale was dichotomised so that 'yes definitely' and 'yes probably' were merged to 'yes' and coded as 1, while 'probably not' and 'definitely not' were merged to 'not' and coded as 0 . Two multivariable binary logistic regressions were performed to explore factors associated with antibiotic prescribing despite a throat swab showing no presence of potentially pathogenic bacteria, one regression for each case scenario. Practitioner's age, gender, being senior versus under training and country were independent variables.

The findings in the four regression analyses were compared with statements in the corresponding guidelines (table 1). Adjusted ORs with 95\% CIs are presented. The level of significance was set to 0.05 . The statistics software package SPSS Windows V.25 was used.

\section{Patient and public involvement}

The target population for this study are medical practitioners. Medical practitioners were involved in the planning of this study, and the results will be d'isseminated to medical practitioners. Patients and the public were not involved.

\section{RESULTS}

In total 969 surveys were handed out with 713 (74\%) returned and $680(70 \%)$ had enough information to be analysed (table 2). The 33 returned surveys not included 
Table 2 Response rate and demographic information of participating medical practitioners

\begin{tabular}{|c|c|c|c|c|c|c|}
\hline & Australia & Germany & Sweden & UK & USA & Total \\
\hline Data collection & $\begin{array}{l}\text { May-November } \\
2018\end{array}$ & $\begin{array}{l}\text { January- } \\
\text { October } 2018\end{array}$ & $\begin{array}{l}\text { September 2018- } \\
\text { March } 2019\end{array}$ & $\begin{array}{l}\text { - January-July } \\
2018\end{array}$ & $\begin{array}{l}\text { October 2018- } \\
\text { April } 2019\end{array}$ & \\
\hline Surveys handed out, $n$ & 156 & 273 & 134 & 110 & 296 & 969 \\
\hline Surveys returned, \% (n) & $96(150)$ & $66(181)$ & $79(106)$ & $83(91)$ & $63(185)$ & $74(713)$ \\
\hline \multicolumn{7}{|c|}{ Statement of exam/education, $\mathrm{n}$} \\
\hline $\begin{array}{l}\text { Did not state exam/ } \\
\text { education }\end{array}$ & 9 & 8 & 1 & 1 & 3 & 22 \\
\hline Statement ambiguous & & & 1 & & & 1 \\
\hline $\begin{array}{l}\text { Was not a medical } \\
\text { practitioner }\end{array}$ & & & 5 & & 5 & 10 \\
\hline $\begin{array}{l}\text { Surveys included in } \\
\text { further analysis }\end{array}$ & 141 & 173 & 99 & 90 & 177 & 680 \\
\hline \multicolumn{7}{|c|}{ Experience as medical practitioner, \% (n) } \\
\hline Senior: GP/consultant & $71(100)$ & $88(153)$ & $41(41)$ & $72(65)$ & $80(141)$ & $74(500)$ \\
\hline $\begin{array}{l}\text { Under training: } \\
\text { resident/registrar }\end{array}$ & $29(41)$ & $12(20)$ & $59(58)$ & $18(25)$ & $20(36)$ & $26(180)$ \\
\hline \multicolumn{7}{|l|}{ Practitioners' age } \\
\hline Average age (SD) & $42(11)$ & $52(10)$ & $41(10)$ & $40(9.0)$ & $47(15)$ & $45(12)$ \\
\hline Median age (IQR) & $41(32-50)$ & $51(45-60)$ & $40(33-48)$ & $39(32-48)$ & $45(34-59)$ & $45(34-55)$ \\
\hline $\begin{array}{l}\text { Practitioner of female } \\
\text { gender, \% ( } n \text { ) }\end{array}$ & $44(61)$ & $44(76)$ & $58(57)$ & $67(60)$ & $51(90)$ & $51(344)$ \\
\hline \multicolumn{7}{|l|}{ Year of graduation } \\
\hline $25 \%$ percentile & 1990 & 1987 & 2000 & 1995 & 1987 & 1990 \\
\hline $50 \%$ percentile & 2000 & 1994 & 2009 & 2004 & 2002 & 2000 \\
\hline $75 \%$ percentile & 2011 & 2000 & 2014 & 2010 & 2013 & 2011 \\
\hline
\end{tabular}

in analysis did not clearly state that the respondent was a medical practitioner (table 2).

\section{Primary aims}

The multivariable analysis showed that practitioners were less likely to agree that throat swabs are of importance in Australia (OR 0.40 (95\% CI 0.15 to 0.55$)$ ), Germany (OR 0.20 (95\% CI 0.11 to 0.35$)$ ) and UK (OR 0.15 (95\% CI 0.077 to 0.29$)$ ) compared with practitioners from Sweden or the USA (table 3). Practitioners from Australia, and especially from Germany, perceived blood tests to be of some importance. UK practitioners were more likely than practitioners from other countries to prescribe antibiotics if a throat swab showed no growth of any potentially pathogenic bacteria. Practitioners from Germany, the USA and especially from Sweden would refrain from antibiotics if a throat swab was negative while practitioners from the UK would be more likely to prescribe antibiotics (table 3).

\section{Secondary aims}

The opinion that throat swabs are of importance was shared by $88 \%$ of participating practitioners in the USA, $87 \%$ in Sweden, $70 \%$ in Australia, $61 \%$ in Germany and $54 \%$ in the UK (table 4). Practitioners from the UK were largely unaware of the existence of $\mathrm{FN}$, while practitioners from Australia and the UK were more likely to prescribe antibiotics to patients with growth of group $\mathrm{C}$ and group G Streptococci (table 5).

Other findings were that older practitioners perceived blood tests such as leucocyte counts, ESR or CRP as important (table 5). However, being a GP or specialist consultant made practitioners perceive blood tests or throat swabs less important compared with medical practitioners in training.

\section{DISCUSSION}

This study found that there were similarities in the perceived best antibiotic prescribing strategy for patients with an apparently uncomplicated acute sore throat between practitioners from countries with very different guidelines. However, the study also found a few significant differences between countries, largely reflecting corresponding differences in guidelines.

\section{Strengths and limitations}

This is the first multinational attempt to link specific differences in guidelines to medical practitioners' perception of best management. The high overall response rate is a strength of the study and indicates the generalisability of our findings. 
Table 3 Perception of relevance of diagnostic tests to guide antibiotic prescribing

\title{
Dependent variables (one multivariable logistic regression for each column)
}

\begin{tabular}{|c|c|c|c|c|}
\hline \multirow{4}{*}{$\begin{array}{l}\text { Independent } \\
\text { variables (practitioner } \\
\text { characteristics) } \downarrow\end{array}$} & \multicolumn{4}{|c|}{ Dependent variables (one multivariable logistic regression for each column) } \\
\hline & \multicolumn{2}{|c|}{ Perceived importance of 'objective' tests } & \multicolumn{2}{|c|}{$\begin{array}{l}\text { Prescribing AB despite negative throat } \\
\text { swab* }^{*}\end{array}$} \\
\hline & $\begin{array}{l}\text { Throat swab } \\
\text { important }\end{array}$ & $\begin{array}{l}\text { Blood tests } † \\
\text { important }\end{array}$ & $\begin{array}{l}\text { Adult patient }(25 \\
\text { years) }\end{array}$ & $\begin{array}{l}\text { Child patient ( } 10 \\
\text { years) }\end{array}$ \\
\hline & aOR $(95 \% \mathrm{Cl})$, p value & aOR $(95 \% \mathrm{Cl}), \mathrm{p}$ value & aOR $(95 \% \mathrm{Cl})$, p value & aOR $(95 \% \mathrm{Cl})$, p value \\
\hline Increasing age (one decade) & $\begin{array}{l}1.2(0.97 \text { to } 1.5) \\
p=0.099\end{array}$ & $\begin{array}{l}1.3(1.1 \text { to } 1.6) \\
p=0.005\end{array}$ & $\begin{array}{l}0.89(0.70 \text { to } 1.1) \\
p=0.35\end{array}$ & $\begin{array}{l}0.88(0.70 \text { to } 1.1) \\
p=0.25\end{array}$ \\
\hline Male gender & $\begin{array}{l}0.72(0.49 \text { to } 1.1) \\
p=0.093\end{array}$ & $\begin{array}{l}0.77(0.53 \text { to } 1.1) \\
p=0.15\end{array}$ & $\begin{array}{l}1.2(0.73 \text { to } 1.8) \\
p=0.54\end{array}$ & $\begin{array}{l}1.3(0.84 \text { to } 2.0) \\
p=0.24\end{array}$ \\
\hline Senior experience $\neq$ & $\begin{array}{l}0.49(0.29 \text { to } 0.86) \\
p=0.012\end{array}$ & $\begin{array}{l}0.52(0.32 \text { to } 0.86) \\
p=0.010\end{array}$ & $\begin{array}{l}1.0(0.55 \text { to } 1.9) \\
p=0.98\end{array}$ & $\begin{array}{l}0.93(0.52 \text { to } 1.6) \\
p=0.80\end{array}$ \\
\hline \multicolumn{5}{|l|}{ Country } \\
\hline Sweden & $\begin{array}{l}0.73(0.34 \text { to } 1.6) \\
p=0.42\end{array}$ & $\begin{array}{l}0.73(0.41 \text { to } 1.3) \\
p=0.28\end{array}$ & $\begin{array}{l}0.35(0.13 \text { to } 0.96) \\
p=0.042\end{array}$ & $\begin{array}{l}0.19(0.069 \text { to } 0.50) \\
p<0.001\end{array}$ \\
\hline UK & $\begin{array}{l}0.15(0.077 \text { to } 0.29) \\
p<0.001\end{array}$ & $\begin{array}{l}1.2(0.72 \text { to } 2.2) \\
p=0.44\end{array}$ & $\begin{array}{l}3.2(1.7 \text { to } 6.1) \\
p<0.001\end{array}$ & $\begin{array}{l}1.7(0.95 \text { to } 3.1) \\
p=0.075\end{array}$ \\
\hline USA (reference) & (reference) & (reference) & (reference) & (reference) \\
\hline \multicolumn{5}{|l|}{ Model evaluation and validation } \\
\hline Included in analysis & 640 & 632 & 631 & 621 \\
\hline Naegelkerke $\mathrm{R}^{2}$ & 0.16 & 0.21 & 0.089 & 0.10 \\
\hline Hosmer \& Lemeshow§ & $11, p=0.23$ & $5.6, p=0.70$ & $4.1, p=0.85$ & $4.8, p=0.78$ \\
\hline
\end{tabular}

Statistically significant findings are presented as bold

\begin{abstract}
exudate, tender anterior lymph nodes and temperature of $38.3^{\circ} \mathrm{C}\left(100.94^{\circ} \mathrm{F}\right)$. A throat swab was taken the day before showing no growth of any potentially pathogenic bacteria.

†Blood tests with elevated inflammatory markers such as leucocytes, erythrocyte sedimentation rate or CRP.

$\ddagger$ Senior experience such as general practitioner/consultant versus practitioner under training (registrar/resident).

$\S X^{2}, p$ value.

IArea under curve $(95 \% \mathrm{Cl})$ and $\mathrm{p}$ value obtained at a receiver operating curve analysis.

aOR, adjusted OR; CRP, C reactive protein.
\end{abstract}

*Scenario with a patient presenting with a 3-day history of a sore throat and no cough. Physical examination shows red tonsils with a tonsillar

The main limitation is that this study measured perceptions and not actual behaviour. Furthermore, being of a cross-sectional design, this study cannot clarify if the association between guidelines and medical practitioners' perception should be interpreted so that guidelines directly caused the perceptions of the medical practitioners to change. Although this is a possible interpretation, given that observed differences in perceptions correspond well with differences in guidelines, it could not be directly proven by this study. It is also possible that guidelines reflect usual practice and availability of rapid tests in a country, and in effect the guideline is influenced by (rather than influences) usual practice.
Sweden and Germany have guidelines that can be considered as nationwide guidelines for PHC in these countries. The situation is somewhat less clear in other countries where different guidelines exist. However, we believe most Australian GPs would rely on the therapeutic guidelines. ${ }^{34}$ The different US guidelines for management of patients with a sore throat are very similar. Most UK guidelines would not encourage throat swabbing. We have chosen to include the guidelines most likely to be used by the practitioners responding to the survey.

The propensity of patients in different countries to visit the medical practitioners with a sore throat is likely to be an interplay between guidelines, organisation of PHC and 


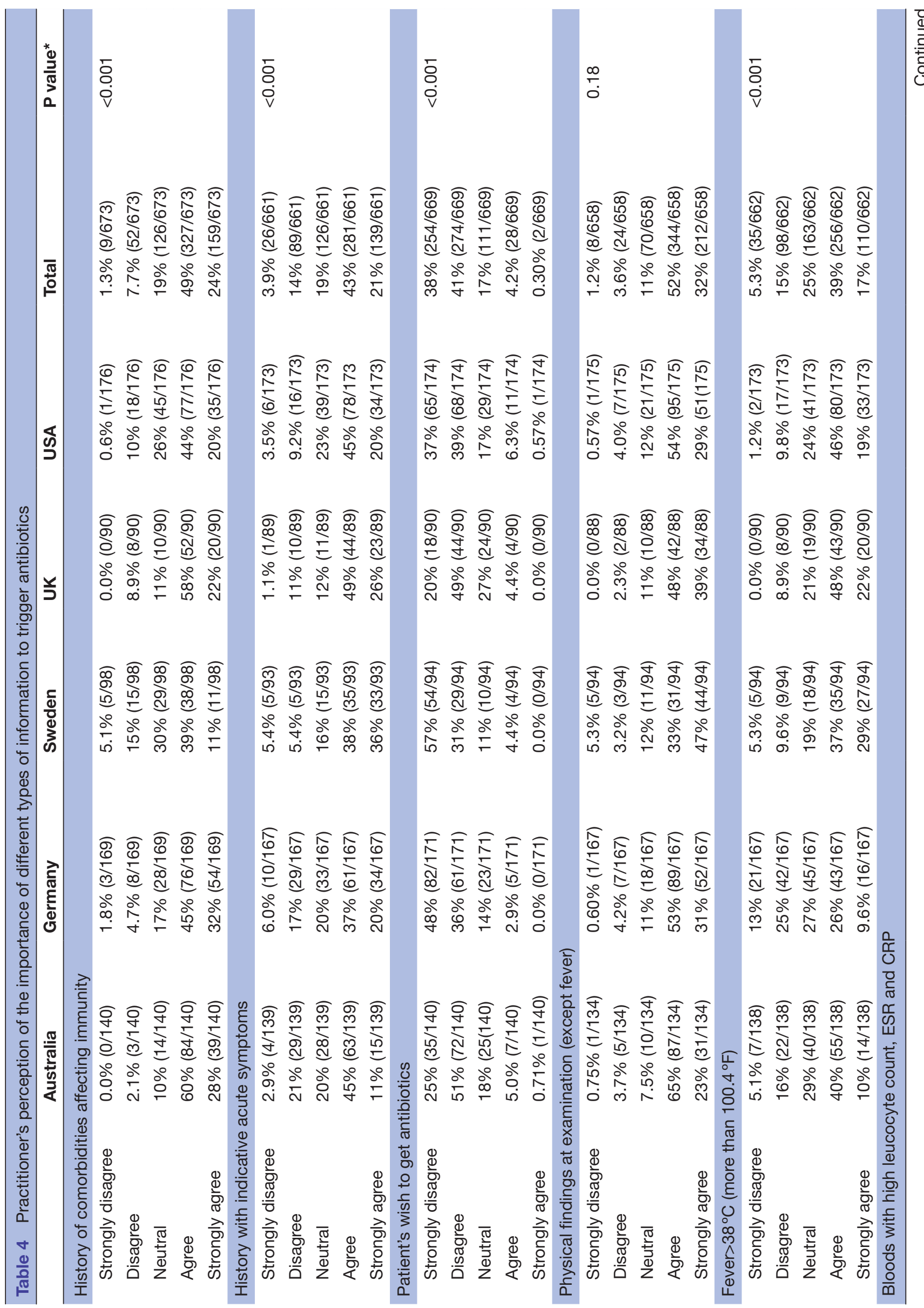




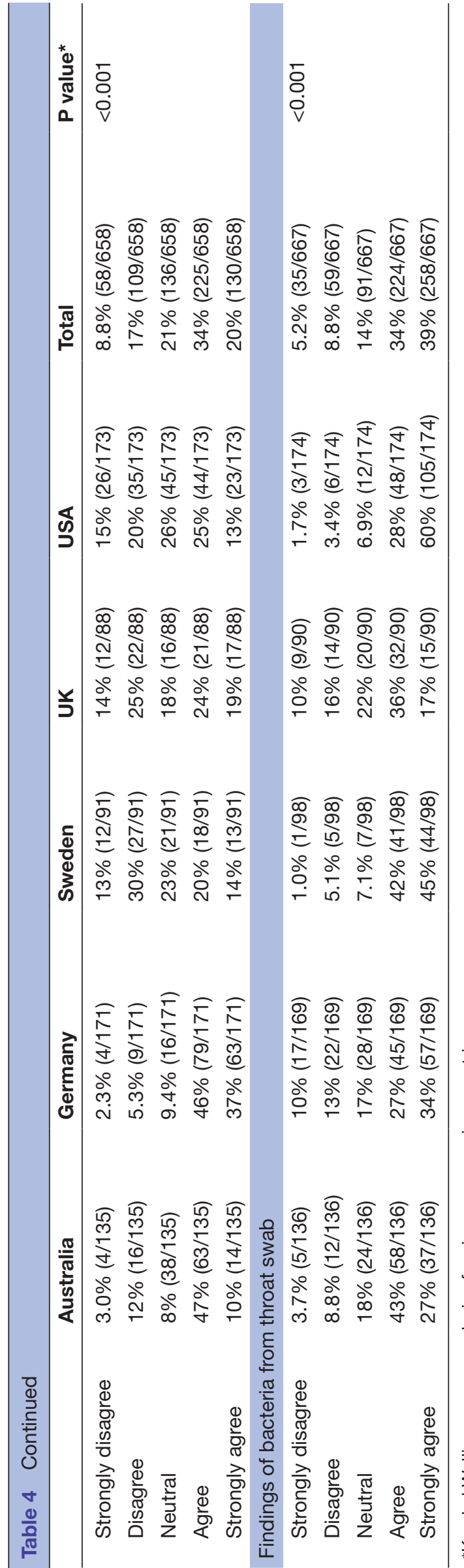

patient behaviour. This may influence the sorts of sore throats that are presented in each country. It was deemed very difficult to show exactly how this phenomenon varied between countries and possibly influenced the result.

Perception of the value of history, physical examination, throat swabs or blood tests may refer either to the importance of doing/obtaining/ordering these yourself or to the importance of the outcome of them. When the practitioner perceives that ordering swabs or blood tests is important, it would obviously mean to look at the results and consider them in management decisions. Hence, for this particular scenario these two aspects of perception are likely to overlap significantly and represent the same perception.

The perception of the clinical value of throat swabbing might be influenced by reimbursement to the doctor for using POCT to detect GAS. POCTs to detect GAS are not reimbursed in Australia, Sweden or the UK. POCTs are reimbursed in the USA and in Germany for patients $<16$ years.

The selection of medical practitioners is a convenience sample and not a random sample. However, practitioners were not approached based on their interest of the topic, only by the fact that they happened to attend a formal meeting held for other reasons. In most highincome countries, medical practitioners are expected to participate in continuous professional education. This is formally checked and followed up in some countries, while in other countries, it is more of a strong encouragement without a formal follow-up. Participation in continuous professional education is likely to be higher now compared with 20 years ago. Hence, practitioners attending an educational meeting is likely a smaller selection bias today compared with 20 years ago.

\section{The perceived importance of a throat swab}

The Swedish and the USA guidelines put a strong emphasis on the importance of a throat swab, while the Australian and UK guidelines are of the opposite opinion. The German guidelines are somewhere in between. These differences in guidelines were clearly reflected where practitioners from Australia, Germany and the UK would be much less inclined to consider a throat swab being of any clinical importance (table 3 ). The lowest clinical value of a throat swab (OR of 0.15 ) was stated by medical practitioners from the UK, and their guideline was the only one that actively discouraged clinicians from using a throat swab.

The guidelines clearly reflect the practitioner's perception of the clinical value of a throat swab, but it is hard to tell which one is the chicken or the egg, if either. A possible alternative explanation is that throat swabs were more commonly used, and therefore valued, where it was reimbursed by national or private health insurance programmes. Throat swabs were to a larger extent perceived as clinically important in Sweden and the USA compared with the other countries. However, throat swabs are reimbursed in the USA but not in Sweden making this interpretation less likely. 


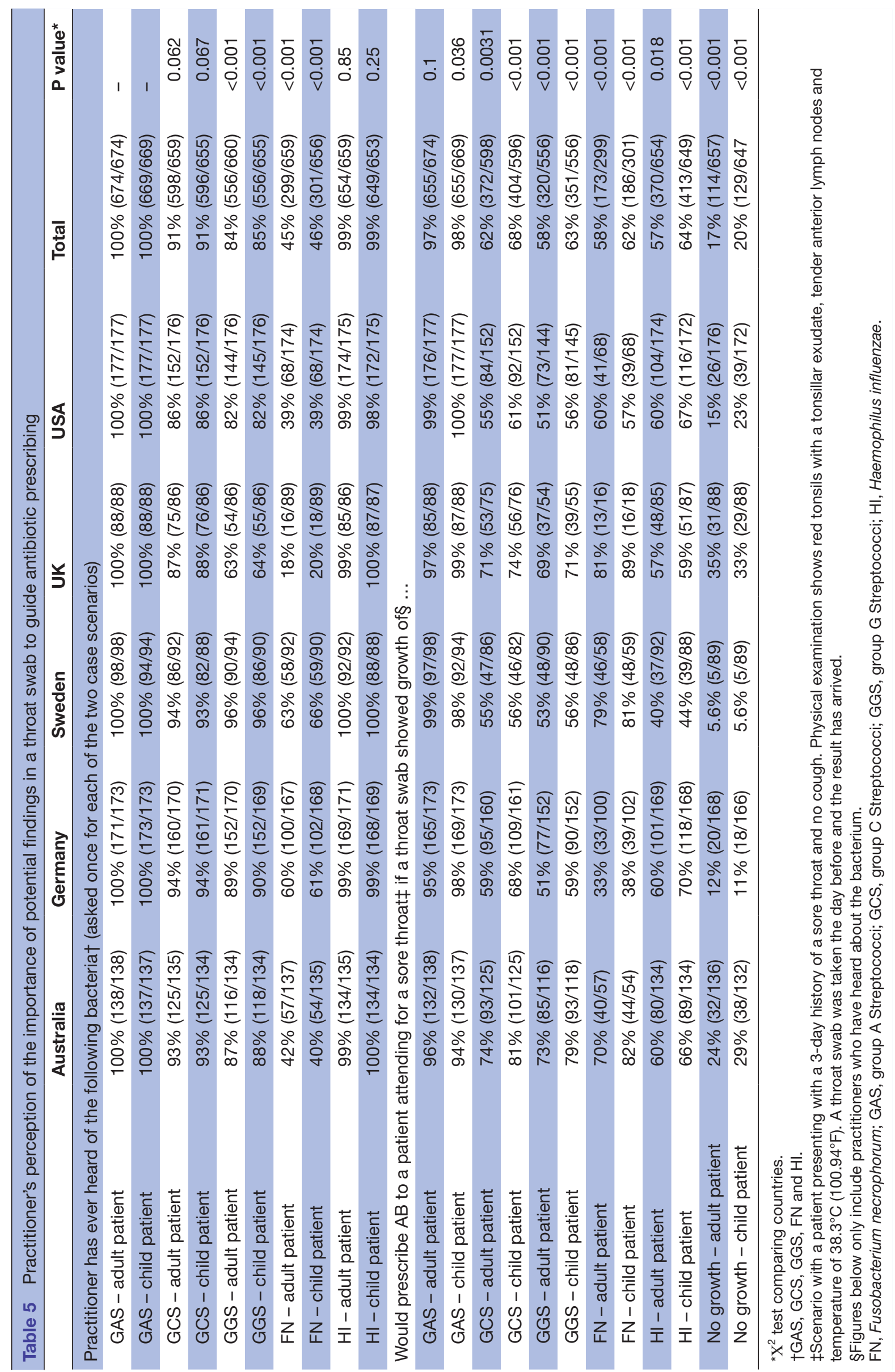

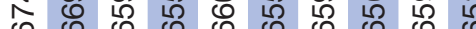
न के $\infty$ uे 0 के

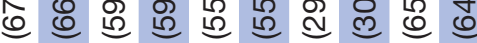

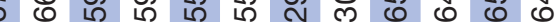

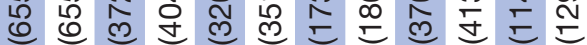

ॠ

ద

te

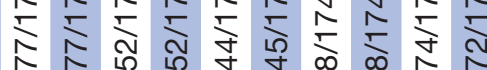
E E ᄃ E E

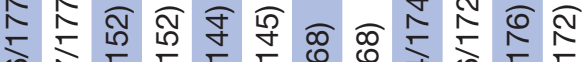

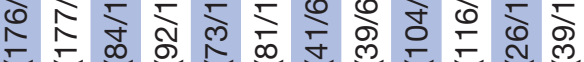

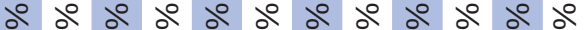

๘

৪ 8 in $\overline{0}$ in

ब్

क

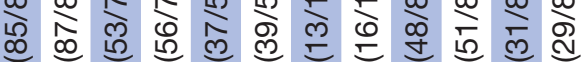

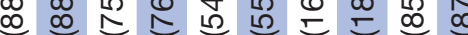

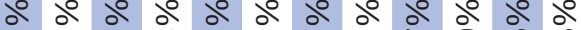

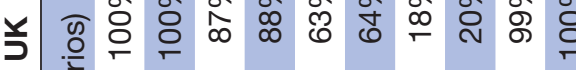
必

 ᄃ

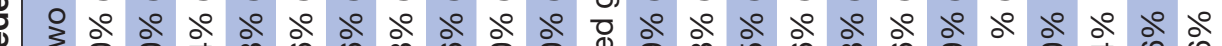

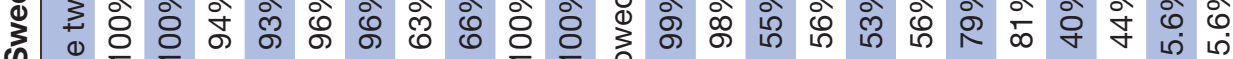

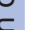

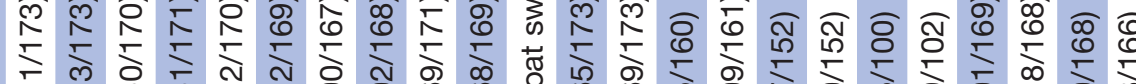

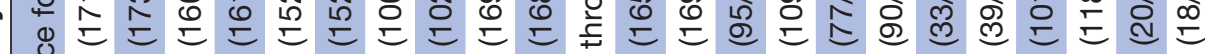

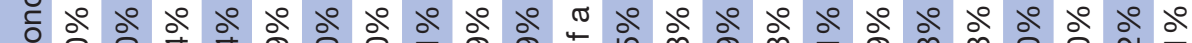

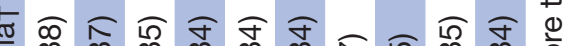

m m m m m

읃

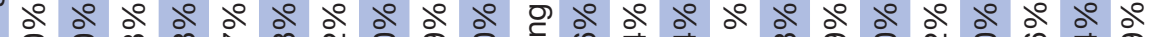

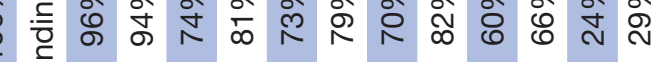

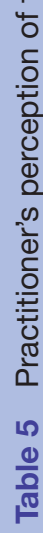

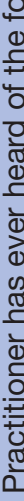

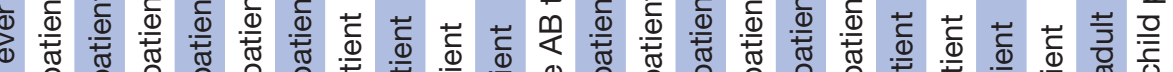

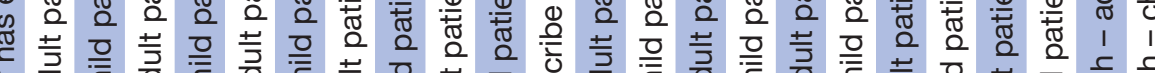

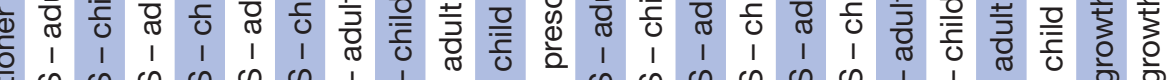
焉 


\section{The perceived importance of blood tests}

The German guidelines discussed the potential value of CRP, while other guidelines mostly disregarded the subject of blood tests or briefly stated blood tests were of no value. Hence, the finding that German practitioners put more emphasis on the clinical value of blood tests (OR 7.3) (table 3) is not surprising.

The finding that increasing age of the practitioner is associated with relying more on blood tests and that being senior (specialists in general practice/family medicine) is associated with relying less on blood tests may at first seem contradictory. However, it could be explained that older practitioners rely more on blood tests because that was more common in the past. During registrar/resident training, medical practitioners are taught to not rely on blood tests for sore throat patients. So, after completing the training and becoming a specialist, they should know blood tests add very little information in patients with a sore throat. There was likely a substantial proportion of practitioners being specialists and still also being quite young.

\section{Antibiotic prescribing to patients with no growth of potentially pathogenic bacteria}

Practitioners in countries with guidelines discouraging the use of throat swabs, such as in Australia and the UK, are more prone to ignore a throat swab showing no growth of any potentially pathogenic bacteria (table 3 ). Countries with a strong emphasis on the clinical importance of throat swabs, such as Sweden and the USA, are much less prone to prescribe antibiotics if a throat swab shows no pathogens. Practitioners from Germany did not perceive a throat swab as important, but they had a tendency to respect a negative throat swab (table 5). Hence, the guidelines seem to reflect the practitioner's perceptions.

\section{Generalisability}

More than one country represented each of the two major types of guidelines recommending or discouraging the use of throat swabs. The perceived value of taking a throat swab was consistent with the corresponding guideline in each country. The subsequent perceived importance of not prescribing antibiotics in case of a negative throat swab also followed the corresponding guideline although these findings were not statistically significant for Australia. The main finding that guidelines seem to reflect medical practitioners' perception is likely to be generalisable to high-income countries.

Differences in populations propensity to attend healthcare, culture among practitioners as well as organisation of funding for PHC make the consumption of antibiotics significantly different between many high-income countries. The main purpose with this manuscript is to make a brief attempt to quantify these differences and identify some factors related to them using the sore throat as a straight forward example. However, the uncomplicated sore throat is just one of many conditions involved. More importantly, this publication aim to stress the importance of a structured international dialogue to sort out these differences that are astonishing given that we all have access to the same evidence.

\section{CONCLUSIONS}

Guidelines describing the optimal management of patients with an apparently uncomplicated acute sore throat differ significantly between countries. The guidelines studied are based on the same scientific studies yet being interpreted very differently. It also seems that medical practitioners in different countries have different perceptions on how to best manage these patients reflecting these differences in guidelines. It would be important to try to agree on a best practice for patients at low risk for rheumatic fever attending for an apparently uncomplicated acute sore throat that can be recommended across many high-income countries. This international guideline should address the use of throat swabs as well as defining etiologic agents where it may be relevant to consider antibiotics.

\section{Author affiliations}

${ }^{1}$ General Practice / Family Medicine, School of Public Health and Community Medicine, Institute of Medicine at University of Gothenburg, Gothenburg, Sweden ${ }^{2}$ Research, Development, Education and Innovation, Primary Health Care, Region Västra Götaland, Gothenburg, Sweden

${ }^{3}$ Centre for Antibiotic Resistance Research (CARe), University of Gothenburg, Gothenburg, Sweden

${ }^{4}$ Department of Epidemiology and Biostatistics, University of Georgia, Athens, Georgia, USA

${ }^{5}$ Faculty of Medicine, Institute for General Practice, Christian-Albrechts-Universität zu Kiel, Kiel, Germany

${ }^{6}$ Cairns Clinical School, James Cook University College of Medicine and Dentistry, Cairns, Queensland, Australia

${ }^{7}$ Centre for Academic Primary Care, NIHR School for Primary Care Research, Population Health Sciences, University of Bristol Medical School, Bristol, UK

${ }^{8}$ Centre for Academic Primary Care, University of Bristol, Bristol, UK

${ }^{9}$ Linköpings universitet Institutionen för medicin och hälsa, Linkoping, Sweden

${ }^{10}$ Futurum Academy of Health and Care, Jonkoping, Sweden

Contributors $R G$ was responsible for conception of the idea. The overall design of the study was made by RG, NM and LR with assistance from SM and P-DS. All authors were involved in the process of acquiring ethics approval and data collection. Statistical analysis was made by RG. RG was the lead in interpretation of results and writing of manuscript, but all authors participated actively in this. All authors approved the final version of the manuscript.

Funding Funding for this project came from the Local Research and Development Council, Södra Älvsborg, Sweden (reference number VGFOUSA-772171 and VGFOUSA-804631).

Competing interests None declared.

Patient and public involvement Patients and/or the public were not involved in the design, or conduct, or reporting, or dissemination plans of this research.

Patient consent for publication Not required.

Ethics approval This prospective cross-sectional study was approved by the ethics committee in Australia (the Human Research Ethics Committee at James Cook University reg number H6993), Germany (Ethik-Komission der Medizinischen Fakultät der Christian-Albrechts-Universität zu Kiel reg number D 576/17), Sweden (the regional ethical review board in Gothenburg reg number 401-18), UK (Health Science Faculty Research Ethics Committee, reg number 58742) and the USA (University of Georgia Institutional Review Board).

Provenance and peer review Not commissioned; externally peer reviewed.

Data availability statement Data are available in a public, open access repository. The raw data file is accessible at https://doi.org/10.5878/45kw-6408 (information is first presented in Swedish but there is a link to get the presentation in English). 
Open access This is an open access article distributed in accordance with the Creative Commons Attribution Non Commercial (CC BY-NC 4.0) license, which permits others to distribute, remix, adapt, build upon this work non-commercially, and license their derivative works on different terms, provided the original work is properly cited, appropriate credit is given, any changes made indicated, and the use is non-commercial. See: http://creativecommons.org/licenses/by-nc/4.0/.

ORCID iDs

Ronny Gunnarsson http://orcid.org/0000-0001-9183-3072

Mark H Ebell http://orcid.org/0000-0003-3228-2877

\section{REFERENCES}

1 Luo R, Sickler J, Vahidnia F, et al. Diagnosis and management of group A streptococcal pharyngitis in the United States, 2011-2015. BMC Infect Dis 2019;19:193.

2 Tran J, Danchin M, C Steer A, et al. Management of sore throat in primary care. Aust J Gen Pract 2018;47:485-9.

3 Gulliford MC, Dregan A, Moore MV, et al. Continued high rates of antibiotic prescribing to adults with respiratory tract infection: survey of 568 UK general practices. BMJ Open 2014;4:e006245.

4 Patel C, Green BD, Batt JM, et al. Antibiotic prescribing for tonsillopharyngitis in a general practice setting: can the use of modified Centor criteria reduce antibiotic prescribing? Aust J Gen Pract 2019;48:395-401.

5 Dallas A, van Driel M, Morgan S, et al. Antibiotic prescribing for sore throat: a cross-sectional analysis of the ReCEnT study exploring the habits of early-career doctors in family practice. Fam Pract 2016;33:302-8.

6 Tyrstrup M, van der Velden A, Engstrom S, et al. Antibiotic prescribing in relation to diagnoses and consultation rates in Belgium, the Netherlands and Sweden: use of European quality indicators. Scand J Prim Health Care 2017;35:10-18.

7 Catanzaro FJ, Stetson CA, Morris AJ, et al. The role of the streptococcus in the pathogenesis of rheumatic fever. Am J Med 1954;17:749-56.

8 Lennon D, Anderson P, Kerdemilidis M, et al. First presentation acute rheumatic fever is preventable in a community setting: a schoolbased intervention. Pediatr Infect Dis J 2017;36:1113-8.

9 Robertson KA, Volmink JA, Mayosi BM. Antibiotics for the primary prevention of acute rheumatic fever: a meta-analysis. $B M C$ Cardiovasc Disord 2005;5:11.

10 Spinks A, Glasziou PP. Antibiotics for sore throat. Cochrane Database Syst Rev 2013;11:CD000023.

11 André $\mathrm{M}$, Hedin K, Håkansson $\mathrm{A}$, et al. More physician consultations and antibiotic prescriptions in families with high concern about infectious illness-adequate response to infection-prone child or selffulfilling prophecy? Fam Pract 2007;24:302-7.

12 OECD Indicators. Health at a glance 2015. Paris: OECD Publishing, 2015.

13 Tyrstrup M. Quality in antibiotic prescribing in primary care. Current practice, relation to guidelines and antimicrobial resistance [Doctoral dissertation]. Lund University, 2017.

14 Barnett ML, Ray KN, Souza J, et al. Trends in telemedicine use in a large commercially insured population, 2005-2017. JAMA 2018;320:2147-9.

15 Martinez KA, Rood M, Jhangiani N, et al. Association between antibiotic prescribing for respiratory tract infections and patient satisfaction in direct-to-consumer telemedicine. JAMA Intern Med 2018:178:1558-60.

16 Pitts J, Vincent S. What influences doctors' prescribing? sore throats revisited. J R Coll Gen Pract 1989;39:65-6.

17 Howie JG. Some non-bacteriological determinants and implications of antibiotic use in upper respiratory tract illness. Scand J Infect Dis Suppl 1983;39:68-72.

18 Cars H, Håkansson A. To prescribe-or not to prescribe-antibiotics. District physicians' habits vary greatly, and are difficult to change. Scand J Prim Health Care 1995;13:3-7.
19 Steffensen FH, Schønheyder HC, Sørensen HT. High prescribers of antibiotics among general practitioners--relation to prescribing habits of other drugs and use of microbiological diagnostics. Scand J Infect Dis 1997;29:409-13.

20 Ashworth $\mathrm{M}$, White $\mathrm{P}$, Jongsma $\mathrm{H}$, et al. Antibiotic prescribing and patient satisfaction in primary care in England: cross-sectional analysis of national patient survey data and prescribing data. $\mathrm{Br} \mathrm{J}$ Gen Pract 2016;66:e40-6.

21 Skoglund I, Segesten K, Björkelund C. GPs' thoughts on prescribing medication and evidence-based knowledge: the benefit aspect is a strong motivator. A descriptive focus group study. Scand J Prim Health Care 2007;25:98-104.

22 Linder JA, Chan JC, Bates DW. Evaluation and treatment of pharyngitis in primary care practice: the difference between guidelines is largely academic. Arch Intern Med 2006;166:1374-9.

23 Rico-Ferreira P, Palazón-Bru A, Calvo-Pérez M, et al. Nonadherence to guidelines for prescribing antibiotic therapy to patients with tonsillitis or pharyngotonsillitis: a cross-sectional study. Curr Med Res Opin 2015;31:1319-22.

24 Gröndal H, Hedin K, Strandberg EL, et al. Near-patient tests and the clinical gaze in decision-making of Swedish GPs not following current guidelines for sore throat - a qualitative interview study. BMC Fam Pract 2015;16:81.

25 Hedin K, Strandberg EL, Gröndal H, et al. Management of patients with sore throats in relation to guidelines: an interview study in Sweden. Scand J Prim Health Care 2014;32:193-9.

26 Cordoba G, Siersma V, Lopez-Valcarcel B, et al. Prescribing style and variation in antibiotic prescriptions for sore throat: cross-sectional study across six countries. BMC Fam Pract 2015;16:7.

27 O'Connor R, O'Doherty J, O'Regan A, et al. Antibiotic use for acute respiratory tract infections (ARTI) in primary care; what factors affect prescribing and why is it important? A narrative review. Ir J Med Sci 2018;187:969-86.

28 McKay R, Mah A, Law MR, et al. Systematic review of factors associated with antibiotic prescribing for respiratory tract infections. Antimicrob Agents Chemother 2016;60:4106-18.

29 Milos V, Jakobsson U, Westerlund T, et al. Theory-based interventions to reduce prescription of antibiotics--a randomized controlled trial in Sweden. Fam Pract 2013;30:634-40.

30 Coxeter P, Del Mar CB, McGregor L, et al. Interventions to facilitate shared decision making to address antibiotic use for acute respiratory infections in primary care. Cochrane Database Syst Rev 2015;11:CD010907.

31 Hoare KJ, Ward E, Arroll B. International sore throat guidelines and international medical graduates: a mixed methods systematic review. $J$ Prim Health Care 2016;8:20-9.

32 Pulcini C, Pauvif L, Paraponaris A, et al. Perceptions and attitudes of French general practitioners towards rapid antigen diagnostic tests in acute pharyngitis using a randomized case vignette study. $J$ Antimicrob Chemother 2012;67:1540-6.

33 Llor C, Vilaseca I, Lehrer-Coriat E, et al. Survey of Spanish general practitioners' attitudes toward management of sore throat: an internet-based questionnaire study. BMC Fam Pract 2017;18:21.

34 Antibiotic. Egf. Acute pharyngitis and/or tonsillitis. therapeutic guidelines (eTG Complete). Melbourne: Therapeutic Guidelines Limited, 2014.

35 Halsschmerzen. DEGAM-Leitlinie: Deutsche Gesellschaft für Allgemeinmedizin und Familienmedizin, 2009.

36 Handläggning AV faryngotonsilliter I öppenvård - NY rekommendation. Information från Läkemedelsverket 2012;6:18-25.

37 NICE. NICE Guideline [NG84]. Sore throat (acute): antimicrobial prescribing: National Institute for health and care excellence (NICE), 2018.

38 Harris AM, Hicks LA, Qaseem A, et al. Appropriate antibiotic use for acute respiratory tract infection in adults: advice for high-value care from the American College of physicians and the centers for disease control and prevention. Ann Intern Med 2016;164:425-34. 